\title{
Effectiveness of School-Based Teaching Program on Knowledge Regarding Recognition and Management of Adolescent's Suicidal Behavior Among School Teachers in Selected Schools in Sikkim
}

\author{
Wanrinylla Marbaniang ${ }^{1}$ Champa Sharma ${ }^{1} \quad$ Arkierupaia Shadap $^{1}$ \\ ${ }^{1}$ Sikkim Manipal College of Nursing, Sikkim Manipal University, \\ Sikkim, India \\ J Health Allied Sci ${ }^{\mathrm{NU}}$ 2022;12:296-301. \\ Address for correspondence Arkierupaia Shadap, MSc (Nursing), \\ Sikkim Manipal College of Nursing, Sikkim Manipal University, \\ Tadong, Gangtok 737102, India \\ (e-mail: shadaparkierupaia@gmail.com).
}

\author{
Abstract \\ Keywords \\ - school-based \\ teaching knowledge \\ - structured teaching \\ program \\ - suicidal behavior \\ - effectiveness \\ - secondary school \\ teachers
}

Objective Suicide is a global public health concern. It is the second leading cause of death among 15 to 29 years old. Suicide ideation often emerges in adolescence and is prevalent among this age group. With the help of leaders, teachers as mentors can play an effective role in the prevention of suicide among children and young adults. The present study was performed to assess the effectiveness of school-based teaching programs on knowledge regarding the recognition and management of adolescent's suicidal behavior among school teachers.

Materials and Methods A quantitative research approach with a pre-experimental (one group pre-test and post-test) research design was adopted. The study was conducted at Government schools of East Sikkim among 80 secondary school teachers. The samples were assigned through the purposive sampling technique. A pre-designed knowledge questionnaire was used to assess the knowledge of schoolteachers. A pretest was conducted during the first week of data collection, which was followed by a school-based teaching program regarding recognition and management of adolescents' suicidal behavior on the second week. A post-test was conducted during the fourth week using the same pre-designed knowledge questionnaire. Data analysis was done using the SPSS version 25 applying descriptive and inferential statistical methods. Results The study findings revealed that in pre-test knowledge score, $5 \%$ had good knowledge, whereas in post-test, score $50 \%$ had good knowledge regarding recognition and management of adolescent's suicidal behavior. The mean score during the pretest was $12.78 \pm 2.87$ and the mean score during the post-test was $16.44 \pm 2.50$. The computed paired " $t$ " value (11.9) was higher than the tabled value $\left(t_{79}=1.99\right.$; $p<0.05)$. An association was found between pre-test knowledge score regarding recognition and management of adolescent's suicidal behavior with gender, religion, and years of working experience at $p<0.05$ level. published online

June 8, 2022
DOI https://doi.org/ $10.1055 / \mathrm{s}-0041-1740333$ ISSN 2582-4287.

\footnotetext{
(c) 2022. Nitte (Deemed to be University). All rights reserved. This is an open access article published by Thieme under the terms of the Creative Commons Attribution-NonDerivative-NonCommercial-License, permitting copying and reproduction so long as the original work is given appropriate credit. Contents may not be used for commercial purposes, or adapted, remixed, transformed or built upon. (https://creativecommons.org/ licenses/by-nc-nd/4.0/) Thieme Medical and Scientific Publishers Pvt. Ltd., A-12, 2nd Floor, Sector 2, Noida-201301 UP, India
} 
Conclusion The study concluded that school-based teaching programs helped secondary school teachers to improve their knowledge regarding adolescents' suicidal behavior. The gain in knowledge from the school-based teaching program will help them recognize and manage adolescents with suicidal behavior and initiate appropriate referrals in the future.

\section{Introduction}

Suicide is a global public health concern. Suicide knows no boundaries and cuts across every sociodemographic level and all regions of the world. A suicide attempt is a crucial risk factor for subsequent suicide. Families, friends, school friends, work colleagues, and communities affected or bereaved by suicide or suicide attempts are often left without assistance. ${ }^{1}$ The World Health Organization (WHO) Mental Health Action Plan 2013-2020 adopted by the World Health Assembly, describes suicide prevention as an important priority for achieving the global target of reducing the rate of suicide in countries by $10 \%$ by 2020 . This action plan highlights that suicide is a serious public health problem worldwide and that with appropriate efforts, suicides are preventable. $^{1}$

According to the WHO, individuals between 10 and 19 years of age come under the adolescent age group. Adolescence is a period of physical growth and intellectual attainment at its peak, coupled with the setting of personality traits, decisions regarding the future profession, and extreme emotional instability. ${ }^{2}$ The majority of suicides have been preceded by warning signs, whether verbal or behavioral. There are some suicides that occur without warning. It is important to understand the warning signs and look out for them. Suicidal people are often ambivalent about living or dying. Some may act impulsively by drinking pesticides and die a few days even though they would like to live. ${ }^{3}$

The WHO recognizes suicide as a public health priority. First WHO World Suicide Report on "Preventing suicide: a global imperative" was published in 2014 and aimed to increase the awareness of the public health significance of suicide and suicide attempts and make suicide prevention a high priority on the global public health agenda. It also aims to encourage and support countries to develop or strengthen comprehensive suicide prevention strategies in a multi-sectoral public health approach. ${ }^{3}$

Schools are a unique environment in which to identify and respond to youth suicides risk, yet the research base for school-based suicide prevention programs is limited due to challenges with implementation and evaluation. ${ }^{4}$ Suicide prevention among children and adolescents is, therefore, a high priority. Given the fact that in many countries and regions most people in this age group attend school, this appears to be an excellent place to develop appropriate preventive action. ${ }^{5}$ Teachers can play an active role in suicide prevention by fostering the emotional well-being of all students, not just those already at high risk. Teachers are well-positioned to promote a feeling of connectedness and belonging in the school community. ${ }^{6}$

According to the National Crime Records Bureau (NCRB) report 2015, more than one lakh people die every year due to suicide in India. All India's rate of suicides was 10.6 during 2015 with Pondicherry reporting the highest rate of suicide (43.2), followed by Sikkim (37.5), Andaman and Nicobar Island (28.9), Chhattisgarh and Telangana (27.7) each. ${ }^{7}$ Northeastern states such as Sikkim (37.5), Tripura (19.6), and Mizoram (11.7) top the list for the highest suicide rates in the country. ${ }^{8}$ Sikkim (37.5\%) recorded as the second-highest rate of suicide in the country in terms of suicide. ${ }^{8}$

Sikkim is India's third-richest state (after Delhi and Chandigarh), by per capita income, and its literacy rate is India's seventh-highest. However, it also records India's secondhighest unemployment rate. About $27 \%$ of the state's suicides were related to unemployment and found to be most common among those between 21 and 30 years of age. ${ }^{9}$

Although Sikkim is recorded with a higher suicide rate among adolescents yet there is insufficient research conducted in this area. There is an urgent need to spread awareness regarding the causes and warning signs of suicide. Schoolteachers can play an active role in the recognition and management of adolescents' suicidal behavior in the school setting. Therefore, investigators felt the need to conduct a research study on this topic to assess the knowledge of teachers regarding adolescents' suicidal behavior and provide a school-based teaching program to increase their knowledge.

\section{Operational definition}

1. Suicidal behavior: It refers to any sudden or dramatic change affecting an adolescent's performance, behavior, an overall decline in grades, decrease in effort, isolating one's self, misconduct in the classroom, unexplained or repeated absentees, irritable mood, not paying attention in the class, excessive smoking, drinking or drug (including cannabis) abuse, incidents leading to police involvement, and gradually at risk of mental distress that could cause a person to die.

2. Knowledge: It refers to the awareness that secondary school teachers have regarding recognition and management of adolescents' suicidal behavior that will be assessed through a structured knowledge questionnaire, good, moderate, and poor knowledge.

3. Secondary school teacher: In this study, secondary school teachers refer to those who teach 8th, 9th, and 10th standard students studying in a government school. 
4. Effectiveness: In this study "effectiveness" refers to the outcome of the school-based teaching program in increasing the knowledge of secondary school teachers regarding recognition and management of adolescents' suicidal behavior in schools.

5. School-based teaching program: It refers to the systemic, organized teaching, which provides information on knowledge regarding recognition and management of adolescents' suicidal behavior. It is a single session that takes 45 minutes duration and through face-to-face teaching (offline mode) program.

\section{Objective}

- Assess the knowledge regarding recognition and management of adolescents' suicidal behavior among school teachers.

- Evaluate the effectiveness of school-based teaching programs regarding recognition and management of adolescent' suicidal behavior among school teachers in selected schools.

- Find the association between the pre-test knowledge score with selected demographic variables (age, gender, religion, marital status, educational status, and years of working experience).

\section{Materials and Methods}

The researcher adopted a quantitative research approach with a pre-experimental (one group pre-test-post-test) research design. The study was conducted at selected government schools of East Sikkim among 80 secondary school teachers. The samples were assigned through the purposive sampling technique. Inclusion criteria were school teachers willing to participate, who were available at the time of data collection, and secondary teachers teaching in government schools. The study excluded the school teachers who had attended school-based suicidal prevention programs previously. A pre-designed knowledge questionnaire was used to assess the knowledge of schoolteachers. A total of 26 multiple choice questions comprised questions under the subheadings related to definitions, warning signs, risk factors, prevention, management, and role of teachers were included in the tool. The reliability of the questionnaire was established using the split-half technique and SpearmanBrown prophecy formula. The reliability score was $r=0.74$ and the tool was considered reliable. A pre-test was conducted during the first week of data collection, which was followed by a school-based teaching program regarding recognition and management of adolescents' suicidal behavior on the second week. A post-test was conducted during the fourth week using the same pre-designed knowledge questionnaire. A pilot study was done before conducting the main study. Data were collected after getting clearance from the Institution Ethics Committee, administration, and written consent from the participants. Data analysis was done using SPSS version 25 by applying descriptive and inferential statistical methods.
Table 1 Frequency percentage distribution of demographic proforma of schoolteachers $(N=80)$

\begin{tabular}{|l|l|l|}
\hline Demographic variables & $\begin{array}{l}\text { Frequency } \\
\text { (f) }\end{array}$ & $\begin{array}{l}\text { Percentage } \\
\text { (\%) }\end{array}$ \\
\hline Age (y) & 21 & 21 \\
- 21-30 & 31 & 39 \\
- $41-40$ & 28 & 35 \\
\hline $\begin{array}{l}\text { Gender } \\
\text { - Male }\end{array}$ & \\
- Female & 25 & 31 \\
\hline Religion & 55 & 69 \\
- Hindu & & \\
- Muslim & 58 & 72 \\
- Christian & 3 & 4 \\
- Buddhist & 5 & 6 \\
\hline Marital status & 14 & 18 \\
- Unmarried & & \\
- Married & 22 & 27 \\
- Divorced & 56 & 70 \\
\hline Educational qualification & 15 & 3 \\
- Postgraduate & 62 & 19 \\
• Graduate & 3 & 77 \\
- Higher secondary school & & 4 \\
\hline Year of working experience & 8 & \\
• <1 & 23 & 28 \\
- 1-5 & 18 & 39 \\
- - >10 & 31 & \\
\hline
\end{tabular}

\section{Results}

The demographic proforma of sample characteristics are shown in - Table 1.

Out of 80 samples, the majority (66 [82\%]) had never come across a suicidal case and $14(18 \%)$ had come across a suicidal case (-Fig. 1A).

Out of 18 samples who had come across any suicidal case, $4(22 \%)$ were their students, $2(11 \%)$ were family members, 3 (17\%) were friends, and 9 (50\%) were other people (- Fig. 1B).

Out of 80 samples, the majority (68 [85\%]) had not encountered and 12 (15\%) of the samples had encountered students trying to inflict injury on themselves such as cutting, hitting, burning, and suffocating (-Fig. 2).

Out of 80 samples, the majority (54 [68\%]) discussed with others when they came across a student with suicidal behavior, whereas 26 (32\%) do not discuss with others (-Fig. 3A).

Out of 54 samples that discussed with others when they came across a student with suicidal behavior, $10 \%$ would call his or her parents, $72 \%$ would talk to him or her personally, and $18 \%$ would report the matter to school authorities (-Fig. 3B).

Out of 80 samples, the majority (42 [52\%]) responded that they were not confident to deal with a student showing suicidal behavior, whereas $38(48 \%)$ responded that they were confident to deal with such students (-Fig. 4). 

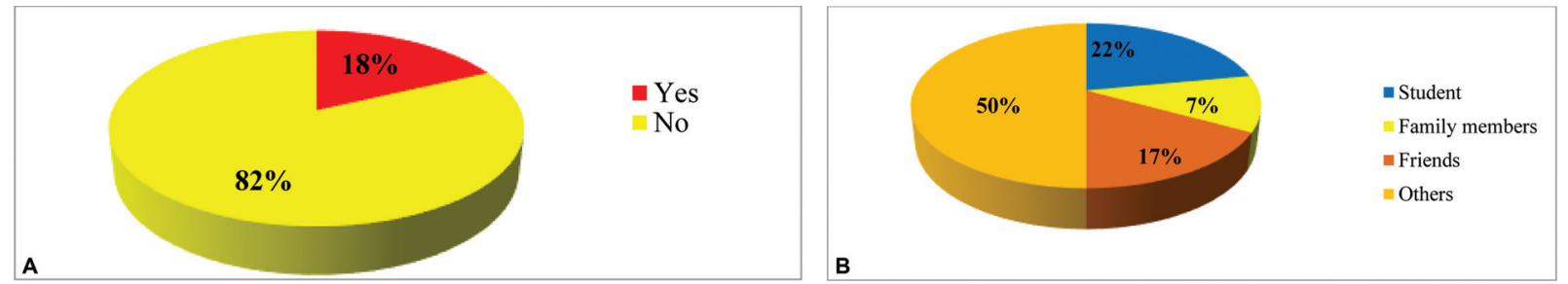

Fig. 1 (A) Pie diagram showing the percentage distribution of samples on whether they have come across any suicidal case $(N=80)$. (B) Pie diagram showing percentage distribution of samples' relationship with the person $(N=18)$.

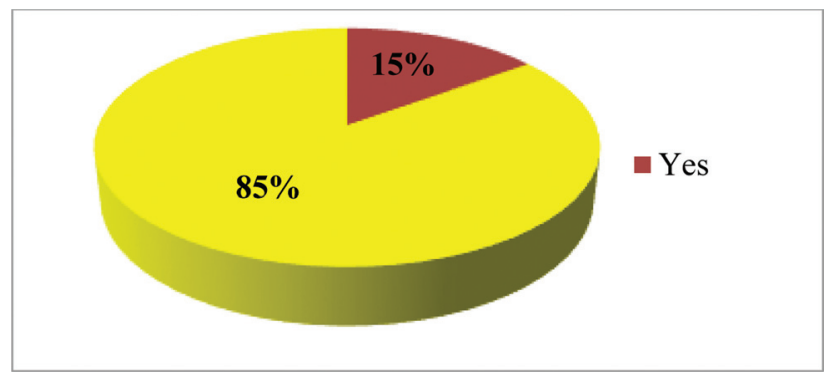

Fig. 2 Pie diagram showing the percentage distribution of samples who had an encounter with students trying to inflict injury on oneself such as cutting, hitting, burning, and suffocating $(N=80)$.

Out of 80 samples, the majority (86\%) responded that they did not have any committee that could deal with students' suicidal behavior and $14 \%$ had a committee that could deal with students' suicidal behavior (-Fig. 5).

- Table 2 shows the frequency and percentage distribution of pretest and posttest knowledge regarding recognition and management of adolescents' suicidal behavior. Pretest knowledge shows the majority (68 [85\%]) had moderate knowledge regarding recognition and management of adolescents' suicidal behavior. Posttest knowledge showed that the majority (40 [50\%]) had good knowledge, 40 (50\%) had moderate knowledge, and none of them had poor knowledge.

- Table 3 shows that the mean post-test knowledge score (16.44) was higher than the mean pre-test knowledge score (12.78) with a mean difference of 3.66. In the pre-test and post-test, standard deviation (SD) values were 2.868 and 2.495 , respectively. The computed " $t$ " value (11.9) was higher than the tabled value $\left(t_{79}=1.99 ; p<0.05\right)$. Therefore, the research hypothesis is accepted.

-Fig. 6 depicts the knowledge of participants in terms of definitions, warning signs, risk factors, prevention, manage-

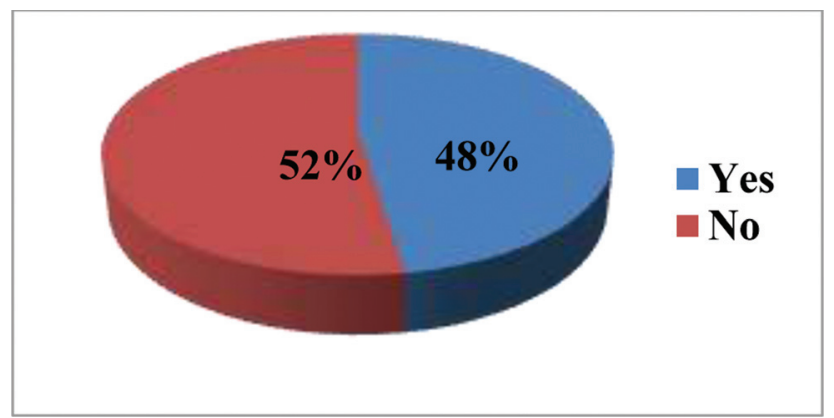

Fig. 4 Pie diagram showing the percentage distribution of samples whether they were confident to deal with a student showing suicidal behavior $(N=80)$.

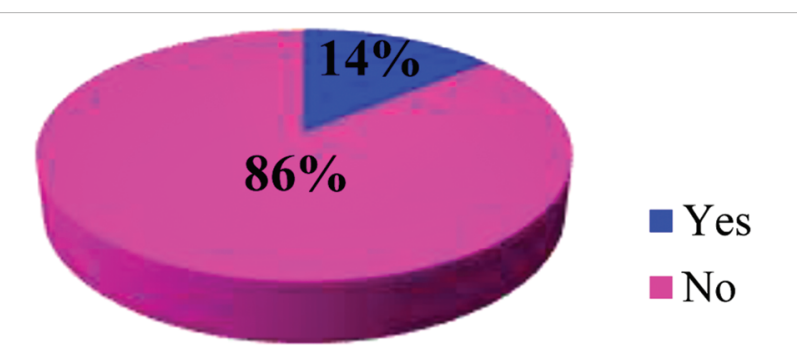

Fig. 5 Pie diagram showing the percentage distribution of samples having a committee that could deal with student's showing suicidal behavior $(N=80)$.

ment, and role of teachers in pre-test was $52.8 \%, 45.3 \%$, $68.4 \%, 29.5 \%$, 54\%, and $48.5 \%$, respectively, whereas the knowledge of participants in post-test was $79 \%, 61.3 \%$, $77.5 \%, 46.3 \%, 62.8 \%$, and $61.3 \%$, respectively. This indicates that there was an increase in knowledge scores in each of the components in the post-test after the school-based teaching program.
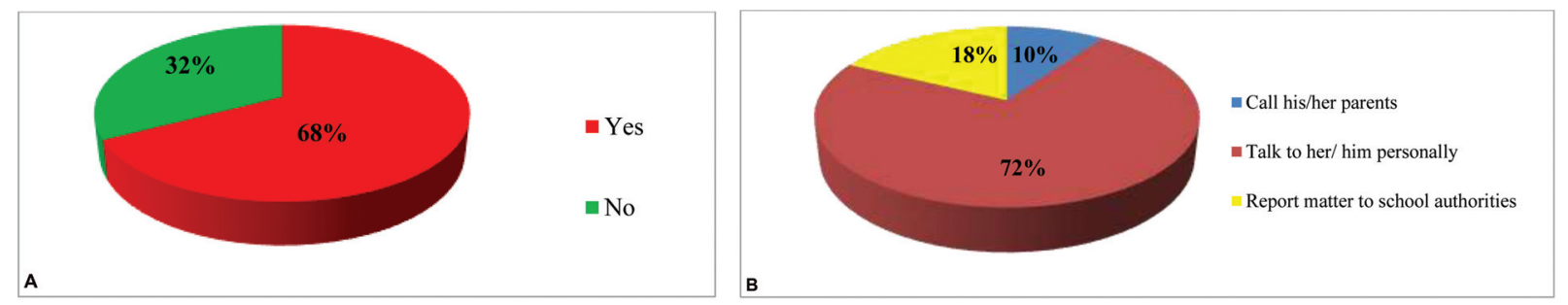

Fig. 3 (A) Pie diagram showing the percentage distribution of samples whether they discussed with others if they come across a student with suicidal behavior $(n=80)$. (B) Pie diagram showing the percentage distribution of samples first response to such student $(N=54)$. 


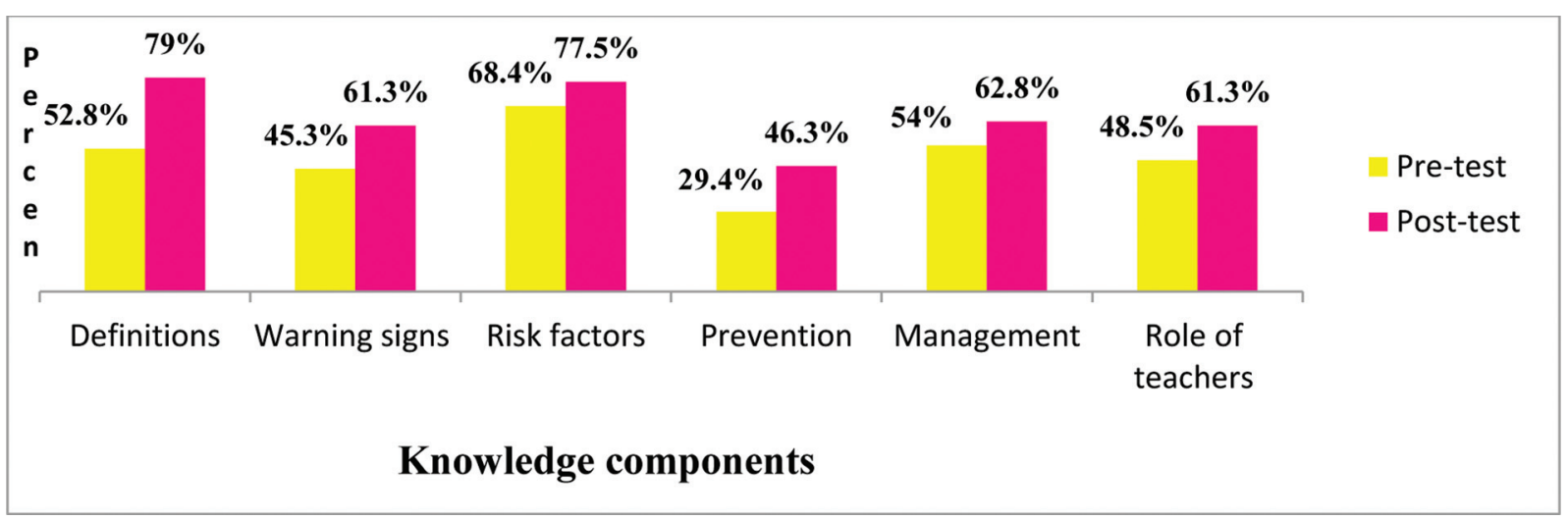

Fig. 6 Bar diagram on components of knowledge on adolescent's suicidal behavior $(N=80)$.

Table 2 Frequency and percentage distribution of pretest and posttest knowledge score regarding recognition and management of adolescent's suicidal behavior $(N=80)$

\begin{tabular}{|l|l|l|l|l|}
\hline \multirow{2}{*}{$T$} & Pre-test & Post-test \\
\cline { 2 - 5 } & (f) & (\%) & (f) & (\%) \\
\hline Poor (0-8) & 8 & 10 & 0 & 0 \\
\hline Moderate (9-16) & 68 & 85 & 40 & 50 \\
\hline Good (17-25) & 4 & 5 & 40 & 50 \\
\hline
\end{tabular}

Table 3 Mean, standard deviation, and paired " $t$ " test value for effectiveness of school-based teaching program among schoolteachers $(N=80)$

\begin{tabular}{|l|l|l|l|l|l|l|}
\hline Knowledge & Mean & SD & $t$-Value & Df & Table value & $p$-Value \\
\hline Pre-test & 12.78 & 2.87 & 11.9 & 79 & 1.99 & .000 \\
\hline Post-test & 16.44 & 2.50 & & & & \\
\hline
\end{tabular}

Note: Significant at $<0.05$ level.

Interpretation: The research hypothesis $\mathrm{H}_{1}$ formulated was thus established because there was a significant difference between the mean knowledge score of pre-test (12.78) and post-test (16.44).

- Table 4 shows findings related to the association between pre-test knowledge score and sample characteristics using the Chi-square test. The data depicted that there was an association between pre-test knowledge scores with gender, religion, and years of working experience. Other demographic variables such as age, marital status, and educational qualification of school teachers were not found to have a significant association with the pre-test level of knowledge regarding recognition and management of adolescent suicidal behavior.

\section{Discussion}

In the present study, pre-test results showed $68(85 \%)$ of schoolteachers had moderate knowledge, 8 (10\%) had poor knowledge, and 4 (5\%) had good knowledge regarding recognition and management of adolescent's suicidal behavior. The study findings were contradicted by a study conducted by Shilubane, Arjan, Ruiter et al among 50 high school teachers in Limpopo Province, South Africa, to assess their knowledge, views, and training needs on the prevention of suicidal behav- ior in students. The results showed that high-school teachers displayed a lack of knowledge of the warning signs of suicidal behavior. They were unaware of the cause of student deaths and did not know how to support students in the event of attempted or completed suicide of another student.

In the present study, the mean post-test knowledge score (16.44) was higher than the mean pre-test knowledge score (12.78) with a mean difference of 3.66. In the pre-test and post-test, SD values were 2.868 and 2.495 , respectively. The computed paired " $t$ " value (11.9) was higher than the tabled value $\left(\mathrm{t}_{79}=1.99 ; p<0.05\right)$. The research hypothesis was accepted. This revealed that the school-based teaching program was effective in increasing the knowledge regarding recognition and management of adolescents' suicidal behavior among schoolteachers. This study was supported by a pre-experimental study conducted by Varughese et $\mathrm{al}^{10}$ on the effectiveness of interactive sessions on the prevention of adolescent suicide among teachers. The study finding showed that in the pre-test, $48 \%$ of the teachers had an average score and $69.1 \%$ had a good score in the post-test, which indicated the effectiveness of interactive sessions on 
Table 4 Association between pre-test knowledge score with selected demographic proforma of schoolteachers $(N=80)$

\begin{tabular}{|c|c|c|c|c|c|}
\hline \multirow[t]{2}{*}{ Demographic characteristics } & \multicolumn{3}{|c|}{ Pre-test knowledge score } & \multirow[t]{2}{*}{ Fisher's exact test $^{\mathrm{a}}$} & \multirow[t]{2}{*}{ Remarks } \\
\hline & Poor & Moderate & Good & & \\
\hline $\begin{array}{l}\text { Age } \\
\quad \text { : 21-30 } \\
\cdot 31-40 \\
\cdot 41 \text { and above }\end{array}$ & $\begin{array}{l}1 \\
1 \\
6\end{array}$ & $\begin{array}{l}19 \\
28 \\
21\end{array}$ & $\begin{array}{l}1 \\
2 \\
1\end{array}$ & 0.113 & $\begin{array}{l}\text { NS } \\
(>0.05)\end{array}$ \\
\hline $\begin{array}{l}\text { Gender } \\
\text { - Male } \\
\text { - Female }\end{array}$ & $\begin{array}{l}5 \\
3\end{array}$ & $\begin{array}{l}20 \\
48\end{array}$ & $\begin{array}{l}0 \\
4\end{array}$ & 0.025 & $\begin{array}{l}\text { S } \\
(<0.05)\end{array}$ \\
\hline $\begin{array}{l}\text { Marital status } \\
\text { - Unmarried } \\
\text { - Married } \\
\text { - Divorced }\end{array}$ & $\begin{array}{l}1 \\
5 \\
2\end{array}$ & $\begin{array}{l}20 \\
48 \\
0\end{array}$ & $\begin{array}{l}1 \\
3 \\
0\end{array}$ & 00.598 & $\begin{array}{l}\text { NS } \\
(>0.05)\end{array}$ \\
\hline $\begin{array}{l}\text { Religion } \\
\text { - Hindu } \\
\text { - Muslim } \\
\text { - Christian } \\
\text { - Buddhist }\end{array}$ & $\begin{array}{l}5 \\
1 \\
0 \\
2\end{array}$ & $\begin{array}{l}50 \\
2 \\
4 \\
12\end{array}$ & $\begin{array}{l}3 \\
0 \\
1 \\
0\end{array}$ & 0.026 & $\begin{array}{l}\text { S } \\
(<0.05)\end{array}$ \\
\hline $\begin{array}{l}\text { Educational Qualification } \\
\text { - Post-graduate } \\
\text { - Graduate } \\
\text { - Higher secondary school }\end{array}$ & $\begin{array}{l}2 \\
6 \\
0\end{array}$ & $\begin{array}{l}12 \\
53 \\
3\end{array}$ & $\begin{array}{l}1 \\
3 \\
0\end{array}$ & 00.678 & $\begin{array}{l}\text { NS } \\
(>0.05)\end{array}$ \\
\hline $\begin{aligned} & \text { Years of working experience } \\
&:<1 \\
&: 1-5 \\
&: 6-10 \\
& \cdot>10\end{aligned}$ & $\begin{array}{l}2 \\
2 \\
0 \\
4\end{array}$ & $\begin{array}{l}5 \\
21 \\
16 \\
26\end{array}$ & $\begin{array}{l}1 \\
0 \\
2 \\
1\end{array}$ & 0.011 & $\begin{array}{l}\text { S } \\
(<0.05)\end{array}$ \\
\hline
\end{tabular}

Abbreviations: $N S=$ non-significant, $\mathrm{S}=$ significant.

${ }^{a}$ Significance of 0.5 level.

improving the knowledge of teachers. The present study findings revealed that there was an association between pre-test knowledge score regarding recognition and management of adolescent's suicidal behavior with gender, religion, and years of working experience at $p<0.05$ level.

\section{Conclusion}

The study concluded that school-based teaching programs helped secondary school teachers to improve their knowledge regarding adolescents' suicidal behavior. The gain in knowledge from the School-Based Teaching Program will help them recognize and manage adolescents with suicidal behavior and initiate appropriate referrals in the future.

\section{Implications}

The findings of the study have several implications in the field of nursing research, nursing education, nursing administration, and nursing practice.

Conflict of Interest

None declared.

\section{Acknowledgments}

The investigators would like to thank the participants in the study, Headmasters of the selected Schools and Prin- cipal SMCON, without whose support and cooperation this study would not have been completed successfully.

\section{References}

1 WHO. National suicide prevention strategies: progress, examples and indicator. 2018. Available at: http://www.who.int. Accessed November 17, $2021>$ mental_health

2 Sreevani R. A Guide to Mental Health and Psychiatric Nursing. 4th ed. New Delhi: Jaypee Brothers; 2016

3 WHO Preventing suicide. A global imperative. 2014 Accessed November 17, 2021 at: http://www.who.int

4 Singer JB, Erbacher TA, Rosen P. School based suicide prevention: a framework for evidenced based practice. 2018 Available at: http:// store.samhsa.gov/shin/content// SMA12-4669/SMA12-4669

5 WHO. Preventing suicide a resource for teachers and other school staff. 2000. Available at: http://www.who.int/mental_health/media/en/

6 Suicide Prevention Resource Centre. The role of high school teachers in suicide prevention resource center. Accessed November 17, 2021 at: https://www.who.int/mental_health/media/en/62.pdf

7 Shilubane HN, Bos AER, Ruiter RAC, van den Borne B, Reddy PS. High school suicide in South Africa: teachers' knowledge, views and training needs. BMC Public Health 2015;15:245

8 National Crime Record Bureau. Chapter 2-Suicides in India. 2015. Available at: http://ncrb.gov.in>accidental deaths and suicides in India. Accessed November 17, 2021

9 Saha D. A student commits suicide every hour in India. India Spend. Published March 18, 2018. Available at: https://www.indiaspend.com/a-student-commits-suicide-every-hour-in-india-3-85917

10 Varughese S, George LS, D'Souza PJ. Effectiveness of interactive session on prevention of adolescent suicide. Manipal Journal of Nursing and Health Sciences 2015;1(02):80-82 